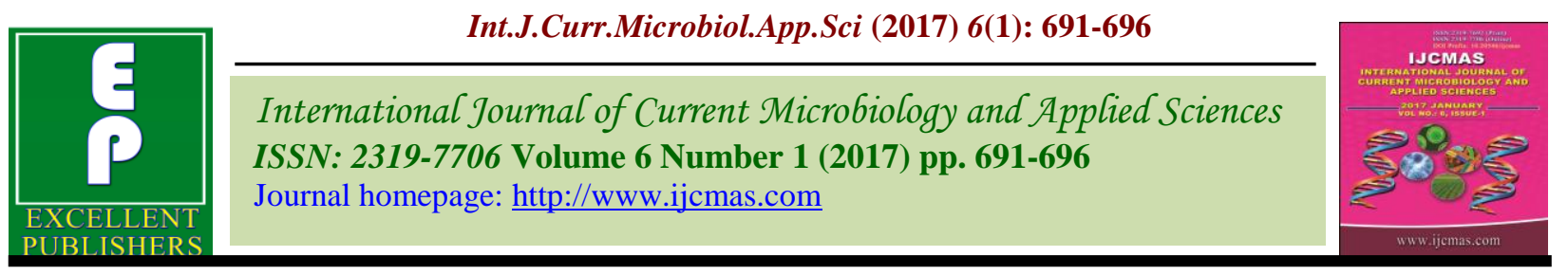

Original Research Article http://dx.doi.org/10.20546/ijcmas.2017.601.083

\title{
Prevalence of HIV Infection among Pregnant Women in a Tertiary Care Hospital Akola, India
}

\author{
Poonam C. Sayare*, Nitin A. Ambhore, Rupali S. Mantri and Rajesh P. Karyakarte \\ Department of Microbiology, Government Medical College, Akola-444005, Maharashtra, India \\ *Corresponding author
}

\author{
A B S T R A C T
}

\section{Keywords}

HIV infection, Prevalence of HIV Infection, Pregnant Women.

Article Info

Accepted:

29 December 2016 Available Online: 10 January 2017
HIV infection in women occurs primarily during their reproductive years, pregnancy provides a opportunity for implementing HIV infection prevention strategies in women. Estimating the rate and trends of HIV seroprevalence among pregnant women provides essential information and monitors its spread within different parts of the country. This study was carried out to estimate the prevalence of HIV infection among pregnant women in tertiary care hospital at Akola. Retrospective hospital record based descriptive study, carried out in Department of Microbiology at Government Medical College, Akola from 2010 to December 2015.HIV antibodies were tested by the three rapid tests protocol as per the guidelines of the World Health Organization and the NACO. 8115 women were ready for counseling and HIV testing under ICTC. Overall, HIV-1 antibodies were detected in 36 out of 8115 of the subject, thus HIV prevalence rate was $0.44 \%$.No pregnant female was found seroreactive for HIV-2 antibodies. Majority of the HIV positive pregnant women (47.22.\%) were in the age group of 25-29 years. Out of 36 HIV positive women, 61.11\% HIV positive women were primigravida and $38.89 \%$ were multigravida. ICTC can provide comprehensive, family centered clinical and supportive services. Thus by estimating seroprevalnce in pregnancy the effective and timely intervention can be undertaken.

\section{Introduction}

AIDS (Acquired Immunodeficiency Syndrome) caused by Human Immunodeficiency Virus (HIV) is a major threat to the global health and development. The consequences of the disease are undeniable. WHO (World Health Organization) stated that global HIV prevalence rate was approximately 35 million in 2013 which constitutes around 3.2 million HIV infected children less than 15 years of age (Praveena et al., 2016). According to $\mathrm{NACO}$, it is estimated that about 30,000 infants acquire infection each year. Mother to child transmission is by far the most significant route of transmission of HIV infection in children below the age of 15 years (NACO, 2006). The transmission may occur late in pregnancy, during labour, delivery and through breast milk. It is estimated that there are between 22,000 and 61,000 pregnant women living with HIV in India. Out of 27 million pregnancies every year, nearly 49,000 are HIV positive pregnancies (WHO, 2011).

Maternal to fetal HIV transmission rate varies from 20 to $25 \%$ in absence of any interventions. HIV infected infants and 
children progress rapidly to AIDS. This transmission of HIV from mother to child can be prevented by appropriate measures (ICMR, 2006). As HIV infections in women occur primarily during their reproductive years, pregnancy provides a unique opportunity for implementing HIV infection prevention strategies in women. The incidence of HIV infections, especially in sexually active young people is the most sensitive marker to track the course of HIV epidemic. It is easy to measure the prevalence in this group by tracking the infection rate among the women during their pregnancies. Accordingly, HIV data from antenatal women has been used to monitor trends in the general population and to predict the seroprevalence in young children (Zaba et al., 2006; Boerma et al., 2003).

Prevention of parent to child transmission of HIV (PPTCT) program has been launched under the NACP in year 2002 (Ashtagi et al., 2011; Sarkate et al., 2015). HIV sentinel surveillance (HSS), data from the pregnant women at antenatal clinics shows considerable difference continue to exist in the prevalence rates across different geographical region of India. Hence, this study was planned to determine the prevalence of HIV infection in pregnant women of a Tertiary Care Hospital, Akola India.

\section{Materials and Methods}

Retrospective hospital record based descriptive study; cross-sectional in design; carried out through the analysis of secondary data collected from ICTC centre; Department of Microbiology at Government Medical College, Akola.

The study included all the pregnant women of ICTC from January 2010 to December 2015. Pregnant women registered at the antenatal clinics of this hospital are routinely advised to undergo HIV screening after pre-test counseling and informed consent. All the essential information was collected from the pregnant women by interviewing them. The variables studied included age, marital status, occupation etc.

Following the guidelines of NACO, the counselor of the ICTC interviewed the pregnant women under strict confidentiality. After pre-test counseling and obtaining consent from them, blood samples were collected. HIV antibodies were tested by the three rapid tests protocol as per the guidelines laid down by the World Health Organization (WHO testing strategy III) and the testing policy of NACO, Government of India (NACO, 2007). Samples tested reactive in the first method were subjected to tests with two different rapid tests, the samples were considered as positive when found reactive by all three different methods. All tests were done according to manufacturer's instructions. Data was collected; compiled and analyzed.

\section{Results and Discussion}

Data was collected and analyzed from pregnant women who were tested during the period of six years from January 2011 to December 2015. 8115 women were ready for counseling and HIV testing under ICTC. Overall, HIV-1 antibodies were detected in 36 out of 8115 of the subject, thus HIV prevalence rate was $0.44 \%$. Prevalence of HIV in antenatal women was highest at 2010, 2012 and 2014 i.e. $0.48 \%, 0.61 \%$ and $0.55 \%$ respectively.

Decrease prevalence is noted in recent year 2015 i.e $0.27 \%$. No pregnant female was found seroreactive for HIV-2 antibodies. A year-wise analysis showed that the number of pregnant women screened for HIV was increased from 2010 (1033) to 2015 (1826). The number of women tested and their prevalence is as in table 1 . 
Majority of the HIV positive pregnant women (47.22.\%) were in the age group of 25-29 years followed by $20-24$ years $(30.56 \%), 30$ 34 years $(13.89 \%), 15-19$ years $(5.55 \%)$ and least in the 35 years and more age group $(2.78 \%)$ (Table 2).

Our of 36 HIV positive women, $61.11 \%$ HIV positive women were primigravida and $38.89 \%$ were multigravida. Socioeconomic profile of pregnant women is depicted in table 3. Education status of 36 HIV positive pregnant women showed that $47.22 \%$ had education was up to primary school level while $27.78 \%$ had up to secondary education, $16.67 \%$ had up to college and above and $8.33 \%$ illiterate. Occupation wise distribution showed that $83.33 \%$ were housewives and $16.67 \%$ were working.

HIV infection was unknown in South East Asian region till 15 years ago but now has become a major challenge to public health. Transmission of HIV infection from mother to child is a major concern for developed as well as developing countrie (Barbicci et al., 1991). Offering HIV testing and counselling to pregnant women provides an opportunity to know their HIV status, take measures to prevent transmission and empower them to make own decisions. It also helps to identify women who are HIV negative and educate them to remain negative.

The prevalence in our study of 8115 women who were accepted HIV testing after pre-test counseling and prevalence of HIV was found to be $0.44 \%$. Similarly studies done by Giri et al., (2012) and Patil et al., (2016) at Maharashtra observed the prevalence of HIV as $0.41 \%$ and $0.44 \%$ respectively. While a study by Gupta et al., (2007) done in North India revealed that the prevalence of HIV was found to be $0.88 \%$. A study conducted by Khokar et al., (2015) at tertiary care Hospital, Gujarat, observed prevalence of HIV as $0.39 \%$. The prevalence of other studies is as follows:

\begin{tabular}{|l|c|l|l|}
\hline Name of the author & Year of study & Place of study & Prevalence \\
\hline Kulkarni et al & 2013 & Maharashtra & 0.76 \\
\hline Sarkate et al & 2015 & Maharashtra & $0.88 \%$ \\
\hline Preethkanwal et al & 2016 & Punjab & $1.03 \%$ \\
\hline Hussain et al & 2016 & Agra & $5.77 \%$ \\
\hline
\end{tabular}

Decrease in prevalence of HIV-AIDS is due increase awareness among society leading to increase in number of pregnant women attending ICTCs. This reflects the importance of trained staff, proper counseling regarding disease, ANC care and institutional delivery. Nowadays knowledge regarding safe sex practices and self-care among students started from teenagers and college level which also shows good impact.

In the present study, out of those $36 \mathrm{HIV}$ positive pregnant women maximum number of clients tested seropositive ie $47.22 \%$ were in the age group of 25-29 years, followed by age group 20-24 years(30.56\%) than older age group. Similar findings are revealed in the study done by Khokar et al., (2015) and Sarkate (2015) et al. This is because of the fact that 25 to 29 years is the most sexually active age group. Young women are more vulnerable to the HIV epidemic and the virus is more easily passed to young women because of their immature vaginal tracts and easily torn tissues; meanwhile, gender inequities in many countries prevent young women from negotiating safer sexual practices including condom use. High prevalence in this group can be considered as forecasting of financial burden as well as loss of youth for the nation (Dash et al., 2012). 
Table.1 Year-wise prevalence rates of HIV infection in pregnant women

\begin{tabular}{|c|c|c|c|}
\hline Year & Total tested & HIV positive & \% positivity \\
\hline 2010 & 1033 & 5 & $0.48 \%$ \\
\hline 2011 & 1288 & 5 & $0.39 \%$ \\
\hline 2012 & 1150 & 7 & $0.61 \%$ \\
\hline 2013 & 1199 & 5 & $0.42 \%$ \\
\hline 2014 & 1619 & 9 & $0.55 \%$ \\
\hline 2015 & 1826 & 5 & $0.27 \%$ \\
\hline Total & 8116 & 36 & $0.44 \%$ \\
\hline
\end{tabular}

Table.2 Age-wise distribution of HIV-Positive pregnant women

\begin{tabular}{|c|c|c|}
\hline Age (years) & HIV Positive & \% Positivity \\
\hline $15-19$ & 2 & 5.55 \\
\hline $20-24$ & 11 & 30.56 \\
\hline $25-29$ & 17 & 47.22 \\
\hline $30-34$ & 5 & 13.89 \\
\hline$>35$ & 1 & 2.78 \\
\hline Total & 36 & 100 \\
\hline
\end{tabular}

Table.3 Socio-demographic factors of HIV positive pregnant women

\begin{tabular}{|c|c|}
\hline \multicolumn{2}{|c|}{ Gravida } \\
\hline Primigravida & $22(61.11 \%)$ \\
\hline Multigravida & $14(38.89 \%)$ \\
\hline \multicolumn{2}{|c|}{ Education } \\
\hline Primary school & $17(47.22 \%)$ \\
\hline Secondary school & $10(27.78 \%)$ \\
\hline College and above & $6(16.67 \%)$ \\
\hline \multicolumn{2}{|c|}{ Occupation } \\
\hline \multicolumn{2}{|c|}{$3(8.33 \%)$} \\
\hline Housewife & $30(83.33 \%)$ \\
\hline Working & $6(16.67 \%)$ \\
\hline
\end{tabular}

Among HIV-positive pregnant women in the present study, majority, $22(61.11 \%)$, were primigravida while $14 \quad(38.89 \%)$ were multigravida. A study done by Patil et al., (2016) also revealed that, out of 309 HIV positive pregnant women studied, majority $166(53.83 \%)$ were primigravida and $143(46.2 \%)$ were multigravida. These findings are also consistence with study by Verma et al., (2002) and Dash et al., (2012).
The percentage of primigravida coming for institutional delivery is significantly more than multigravida, which again suggests the increased awareness of people towards HIV/AIDS.

In our study, $8.33 \%$ of clients were illiterate, $47.22 \%, 27.78 \%, 16.67 \%$ clients have done their primary school, secondary school and college and above education. While study by 
Patil et al., (2016) observed that education status of $36.3 \%$ of HIV positive women was up to secondary level, $31.3 \%$ had primary education only and $21.7 \%$ were illiterate out of 309 ANC women. In comparison to our study, more number of illiterate clients might be due to, that study area belongs to rural area of Maharashtra. It is observed in present study that $83.33 \%$ clients were housewives and $16.67 \%$ clients were working.

In conclusion, this study concludes that recently prevalence rate of HIV in pregnant women is decreasing. This indicates that prevention campaigns are working effectively. ICTC can provides comprehensive, family centered clinical and supportive services by continuous information, education and counseling that empower the pregnant woman to take her own decisions and prevent the transmission of HIV to her infant. Thus by estimating seroprevalance in pregnancy the effective and timely intervention can be undertaken that will reduce the transmission of infection to newborn babies.

\section{Acknowledgments}

The authors are very much thankful to Dr. R.P Karyakarte Sir, Dean, Government Medical College, Akola for his valuable guidance and support. Our sincere gratitude as he has been a constant source of motivations inspiration and motivation for such research activities.

\section{References}

Ashtgi, G., Metgud, C., Walvekar, P., Naik, V. 2011. Prevalence of HIV among Rural Pregnant Women Attending PPTCT Services at KLE Hospital, Belgaum. AJMS, 4(1): 45-8.

Barbicci, M., Repke, J.T., Chaisson, R.E. 1991. Routine Prenatal Screening for
HIV Infection. Lancet, 337: 709-1.

Boerma, J.T., Ghys, P.D., Walker, N. 2003. Estimates of HIV-1 prevalence from national population-based surveys as a new gold standard. Lancet, 362: 19291931.

Dash, M., Mohantay, I., Sahu, S., Narasimham, M., Padhi, S., Panda, P. 2012. Declining hiv seroprevalence among pregnant women in south odisha, india: a six and half year tertiary care hospital based. IJBR, 3(7): 546-51.

Giri, P.A., Bangal, V.B., Phalke, D.B. 2012. Prevalence of HIV among rural pregnant women attending antenatal clinics at Pravara Rural Hospital, Loni, Maharashtra, India. Int. J. Health Allied Sci., 1: 13-5.

Gupta, S., Gupta, R., Singh, S. Seroprevalence of HIV in pregnant women in North India: a tertiary care hospital based study. BMC Infect. Dis., 5: 4-8.

Hussain, T., Kulshreshtha, K.K., Yadav, V.S. 2016. HIV infection among pregnant women attending an integrated counseling \& testing centre at Agra: comparison with studies in other regions of India., 5(1): 90-7.

Indian Council of Medical Research. 2006. National Institute of Medical Statistics. National AIDS Control Organization. Technical report - India HIV estimates -2006. New Delhi, ICMR.

Khokhar, N., Jethwa, D., Lunagaria, R., Panchal, N. 2015. Original Research Article Seroprevalence of Hepatitis B, Hepatitis C, Syphilis and HIV in Pregnant Women in a Tertiary Care Hospital, Gujarat, India. 4(9):188-94.

Kulkarni, S.K., Doibale, M.K. 2013. Trend of seroprevalence of hiv among antenatal clinic attendees at a tertiary care hospital. 3(1): 257-62.

NACO Guidelines for the prevention of 
mother to child transmission of HIV [http://www.naco.nic.in/pmtct.html].

National AIDS Control Organization, Ministry of Health and Family Welfare, Government of India. Detection of HIV infection. In: Guidelines on HIV Testing, March 38-53.

Patil, V.M., Moray, A.P., Patil, S.P. 2016. Ten years' trend of HIV seroprevalence among Indian pregnant women attending antenatal clinic at tertiary hospital in Dhule, Maharashtra, India. 5(5): 1514-9.

Praveena, P., Edward, S., Kannan, L. 2016. A study on cognizance of vertical transmission of HIV/AIDS among pregnant women attending antenatal clinic in a tertiary care hospital, Chennai. Int. J. Community Med. Public Health, 3: 408-13.

Preetkanwal, S., Mohi, M., Kumar, A. 2016. Seroprevalence of Human Immunodeficiency Virus Among
Antenatal Women in One of the Institute of Northern India. J. Clin. Diagnostic Res., 10(9): 10.

Sarkate, P., Paranjpe, S., Ingole, N., Mehta, P. 2015. Monitoring HIV Epidemic in Pregnant Women: Are the Current Measures Enough? Sex Transm. Dis.

Verma, P. 2002. Prevalence of Hiv Among Pregnant Women Attending Antenatal Clinics at a Tertiary Care Hospital in Central India. Indian J. Res., 4(7): 59.

World Health Organization. Joint United Nations Programme on HIV/AIDS, United Nations Children's Fund, Towards Universal Access: Scaling up Priority HIV/AIDS Interventions in the Health.

Zaba, B., Boerma, T., White, R. 2000. Monitoring the AIDS epidemic using HIV prevalence data among young women attending antenatal clinics: prospects and problems. AIDS, 14: $1633-45$.

\section{How to cite this article:}

Poonam C. Sayare, Nitin A. Ambhore, Rupali S. Mantri, Rajesh P. Karyakarte. 2017. Prevalence of HIV Infection among Pregnant Women in a Tertiary Care Hospital Akola, India. Int.J.Curr.Microbiol.App.Sci. 6(1): 691-696. doi: http://dx.doi.org/10.20546/ijcmas.2017.601.083 